\title{
Sujeitos da Decisão de Medida Socioeducativa de Internação Investigando Códigos Ideológicos
}

\author{
Érica Babini Machado \\ Doutora pela Universidade Federal de Pernambuco - Ufpe. \\ Professora de Direito Penal e Criminologia da Universi- \\ dade Católica de Pernambuco - Unicap. Pesquisadora do \\ Grupo Asa Branca de Crimionlogia.
}

\section{Jéssica Bezerra Carvalho}

Graduanda em Direito da Universidade Católica de Pernambuco - Unicap. Pesquisadora do Programa de Iniciação Científica -Pibic/Unicap.

\section{Resumo}

Trata-se de pesquisa que investiga fundamentos das decisões judiciais de imputação de medida socioeducativa de internação proferidas nos anos de 2011 e 2012 nas Varas da Infância de Pernambuco. Objetiva-se compreender se existem códigos ideológicos (second codes) relativos à defesa social presentes na decisão e o grau de influência que exercem na argumentação judicial. Metodologicamente, para extrair as motivações das sentenças foi realizada análise de conteúdo. Trata-se, portanto, de identificar os fundamentos das decisões, cuja hipótese é que são proferidas em razão de estereótipos de raça e condição socioeconômica.

Palavras-chave: Justiça da Infância e Juventude. Estereótipos. Decisões judiciais.

\section{Subject of the decision of juvenile prision: investigating ideological codes}

\section{Abstract}

This research investigates the reasons of the judicicias decisions of juvenile prision made in the year 2011 and 2012 Youth Court of Pernambuco. The problem is to understand whether there are ideological codes (second codes) relating to social defense in the decision and the degree of influence of 
that in the judicial reasoning. Methodologically, was used content analysis. Therefore, it is to identify the reasons of the decisions, whose hypothesis is that they are given due stereotypes of race and social conditions.

Keywords: Justice for Children and Youth. Stereotypes. Judgments.

\section{Sumário}

1 Compreendendo a responsabilização infracional: promessas declaradas de um sistema protetivo. 2 Metodologia de análise: buscando evidências de códigos ideológicos. 3 análise e discussão: das metarregras (a produção de bodes expiatórios) às violações de direitos e garantias fundamentais. 3.1 Metaregras da proteção social e o escamoteamento da punição pela pedagogia da internação. 4 Provocando reflexões. 5 Referências. 


\section{COMPREENDENDO A \\ RESPONSABILIZAÇÃO INFRACIONAL: \\ Promessas Declaradas de um Sistema Protetivo}

Mediante a entrançada relação entres os sujeitos da decisão de medida socioeducativa de internação e a existência de possíveis códigos ideológicos no momento da prolação da sentença, necessário se faz, $a$ priori, a explicação do sistema infracional juvenil e sua evolução, consolidado com as medidas socioeducativas de internação, para que melhor se possa compreender o papel da sociologia jurídica na análise da construção das decisões jurídicas.

A ideia de infância e adolescência não existia anteriormente ao século 19. A visão de infância como uma etapa do desenvolvimento do ser humano, que tem características próprias, bem definidas, ganhou força na Idade Moderna, inserida no contexto social e histórico da modernidade, com o avanço das ciências e as mudanças econômicas (Priore, 1999). A expressão de uma preocupação jurídica deu-se a partir do século 19, especialmente em razão do quadro social na Europa de pobreza e marginalização com a Revolução Industrial e da potencialização dos critérios bioantropológicos do conhecimento médico.

$\mathrm{Na}$ América Latina, o tratamento jurídico diferenciado da infância-adolescência remonta às primeiras décadas do século 20, com assistencialismo e amparo às crianças necessitadas, cujo objetivo seria diminuir a mortalidade infantil desvalida ou moralmente abandonada. Surgiu, a partir de então, um amplo movimento de reformas, cujo resultado foi a instauração de legislações de menores que abriram a possibilidade de intervenção estatal ilimitada. Fez-se necessário, portanto, encontrar um marco jurídico de contenção daqueles que se encontravam aquém do controle e, nesse contexto, as políticas de segregação começaram a adquirir caráter sistemático, sendo legitimadas pelo viés científico do positivismo criminológico e das consequentes teorias da defesa social. 
Essas estratégias legitimadoras foram recepcionadas na América Latina, instalando-se a Doutrina da Situação Irregular ${ }^{1}$ com grande profusão, justificando uma potencial ação judicial indiscriminada sobre as crianças e os adolescentes em situação de dificuldade. Com a consagração da Convenção Internacional sobre os Direitos da Criança, aprovada pela Assembleia Geral das Nações Unidas em 1989, houve uma ruptura com a doutrina de situação irregular para dar lugar à doutrina de proteção integral, consolidada no Brasil pela Constituição da República Federativa do Brasil (1988) e pelo Estatuto da Criança e do Adolescente - ECA (1990).

Tem para si, no entanto, os movimentos sociais de defesa das crianças e adolescentes que o rompimento com a doutrina da situação irregular não foi totalmente assimilado pela sociedade. Ainda há uma forte ideia de segregação da infância, a fazer crer que na América Latina, existiriam dois tipos de infância: uma, com suas necessidades básicas satisfeitas (crianças e adolescentes) e outra, com suas necessidades básicas total ou parcialmente insatisfeitas (os menores) (Méndez, 1998).

Nesse sentido, é de se pressupor uma tendência da inclinação do Judiciário ao encarceramento juvenil, fundamentada seja na crença de que as medidas socioeducativas são definitivamente um programa de socialização destinado àqueles que tiveram a socialização defeituosa, seja em razão da pressão social para a efetiva punição de “jovens delinquentes”, como a mídia estimula.

Na verdade, o pressuposto decorre da criminologia crítica, cujo acúmulo teórico permite identificar uma real e expansiva tendência encarceradora. A criminologia crítica é uma teoria criminológica, de inspiração

\footnotetext{
${ }^{1}$ A Doutrina de Situação Irregular surgiu com a consagração do Código de Menores, Lei $6.697 / 1979$. Sua ideologia baseia-se na ideia do menor como um objeto da norma, quando este encontra-se em situação de patologia social, não ajustado aos padrões estabelecidos. As crianças e jovens seriam, portanto, objetos de proteção, não sendo reconhecidos como sujeitos de direitos, e sim como incapazes.
} 
marxista, concebida por Alessandro Baratta, com base epistemológica na teoria do etiquetamento do sistema penal (labelling approach) (Baratta, 1999), isto é, por considerar o crime um constructo social, resultado de um processo de criminalização, o sistema de justiça criminal opera seletivamente, manipulando a esfera de atuação a pobres, negros, egressos e outras minorias.

A criminologia crítica rompeu com a sociologia criminal liberal, propondo uma mudança de paradigma e explicando os processos de criminalização das classes subalternas, historicamente constituintes da clientela do sistema penal (Andrade, 1997). A teoria do labelling approach, surgida nos EUA na década de 60, propunha que o crime não poderia ser uma realidade ontológica, mas o resultado de um processo condicionado pelo grau menor ou maior de reação social, isto é, na dependência da atuação classificatória do controle social.

Consequentemente, o crime não são todas as transgressões injustificadas à lei penal (dogmática penalista), mas as condutas que a sociedade e seus órgãos punitivos decidem perseguir como tal, com o criminoso sendo o resultado de um etiquetamento social e não o corolário lógico de uma conduta praticada. O labelling approach, entretanto, por si só, não conseguiu romper com a criminologia liberal, porque foi colocado em um contexto subjetivista e idealista. Com a base da criminologia da reação social e com as teorias conflituais não marxistas, tem-se a passagem para as análises críticas, promovendo uma mudança gradual no pensamento criminológico.

A criminologia crítica, portanto, trata o conflito como luta de classes, desenhado diante dos modos de produção e da infraestrutura socioeconômica da sociedade capitalista. É nesse momento que se dá a ruptura do pensamento crítico com aquele liberal. A criminologia crítica recupera, portanto, a análise das condições objetivas, estruturais e funcionais que originam, na sociedade capitalista, os fenômenos de desvio, interpretando- 
-os separadamente conforme se tratem de condutas das classes subalternas ou modos de agir das classes dominantes (a chamada criminalização do colarinho branco, dos detentores do poder econômico e político, a criminalidade organizada, etc.) (Andrade, 1997).

Baseada em algumas constatações como existência da falsidade do discurso penal e a agressão aos direitos humanos em um sistema penal ilegítimo, a criminologia crítica propõe que o estudo criminológico saia de suas premissas fechadas no próprio método e demonstre que o estudo do fato social/crime não pode ser realizado sem uma contextualização maior e mais completa das estruturas da sociedade (Wacquant, 2003).

O compromisso é, portanto, com a transformação da estrutura social, demonstrando a perversidade seletiva do sistema penal. Quanto mais desigual socialmente for a coletividade, mais necessidade ela terá do Direito Penal. Promover um descomprometimento do sistema penal para com os detentores do poder criminalizador é fundamental (Zaffaroni, 2001).

No Brasil, o primeiro filtro estabelecido à criminalização secundária encontra-se nas agências policiais. Finalizado o procedimento investigativo, o inquérito é encaminhado ao Ministério Público, e posteriormente ao Judiciário.

Ao analisar a possibilidade de imputação de responsabilidade, o Ministério Público, por meio da denúncia, exerce o poder de acusar formalmente, fazendo o terceiro filtro no processo de criminalização. Por fim, cabe ao magistrado julgar o caso, absolvendo ou condenando o acusado. Este é um paradoxo entre a ineficiência das agências e dos atores de controle, pois ao investigar e elucidar delitos, o alto grau de punitivismo (pressão social) em tese deveria levar à redução do número de delitos, porém, o que ocorre é o inverso, os números crescem, fazendo com que o público na frenética insegurança demande mais punição. 
Enfim, os principais fatores que produzem ineficácia nos resultados esperados pelo público consumidor do discurso punitivo são o alto grau de seletividade na criminalização secundária, a ausência de imparcialidade nos julgamentos, a cifra oculta de delitos não comunicados às autoridades policiais e a lentidão burocrática das instituições.

Diante da notória seletividade presente no momento da criminalização (secundária), a hipótese é a de que há uma tendência à marginalização dos menores em conflito com a lei, no momento da aplicação das medidas socioeducativas pelos juízes, sob os argumentos de socioeducação e tutela (exatamente os mesmos discursos da Doutrina da Situação Irregular.

É sabido que o poder de um juiz não pode se confundir com o poder de um pai, devendo aquele tratar a criança/adolescente não como objeto, mas como sujeito de seu próprio desejo, intervindo de forma a lhes possibilitar o reconhecimento de sua responsabilidade e de sua própria vontade, mesmo que haja um choque de interesses com os desejos dos pais e dos atores jurídicos (Rosa, 2004).

Considerando os acúmulos teóricos já apresentados, é observado que, diante de lacunas legislativas ainda presentes no ECA, autorizadora do avanço da discricionariedade e do arbítrio na execução das medidas socioeducativas (Saraiva, 2009, p. 122), e da pressão populista de uma sociedade punitivista que demanda segurança pública, há um aumento da seletividade e estigmatização do indivíduo no momento da decisão do magistrado, a qual é proferida, baseada num código ideológico, que influencia o magistrado a decidir não segundo a lei, mas baseado em estereótipos, preconceitos, subjetivismos, o que, para o autoritarismo, é um passo. Vejamos. 


\section{METODOLOGIA DE ANÁLISE: Buscando Evidências de Códigos Ideológicos}

Como o objetivo precípuo na pesquisa é a observação da atuação dos magistrados no momento em que analisam as garantias legais para imputação de medidas socioeducativas de internação, consagradas na doutrina da proteção integral, tentou-se verificar se estavam (ou não) influenciados por "códigos ideológicos".

Para tanto utilizou-se como metodologia, além da revisão bibliográfica para o estabelecimento do marco teórico crítico do sistema punitivo, outra vertente metodológica de cunho qualitativo a fim de que permitisse traçar um diagnóstico de como atuam os magistrados das Varas da Infância e Juventude, para compreender as possíveis influências de pressões sociais, decorrentes de medo e manipulação midiática, configuradores da sociedade punitiva.

A metodologia de cunho qualitativo foi a análise de conteúdo das decisões (Bardin, 1977), um conjunto de técnicas de pesquisa cujo objetivo é a busca do sentido ou dos sentidos de um documento. Segundo este autor, a análise de conteúdo é um conjunto de técnicas de análise das comunicações, que utiliza procedimentos sistemáticos e objetivos de descrição do conteúdo das mensagens, com um rigor de objetividade e uma hermenêutica controlada, a fim de instigar o investigador a buscar o oculto em qualquer mensagem, baseado na dedução, com finalidade na produção de inferências.

Produzir inferências, em análise de conteúdo significa não somente produzir suposições acerca de determinada mensagem, mas embasá-las com pressupostos teóricos de diversas concepções de mundo e com as situações concretas de seus produtores ou receptores. 
Situação concreta que é visualizada segundo o contexto histórico e social de sua produção e recepção (Bardin, 1977). Inferências são, portanto, saberes deduzidos dos conteúdos, que recorrem a indicadores sobre o emissor da mensagem ou sobre seus meios.

Assim, por meio desse método, que pode ser utilizado tanto para análises quantitativas quanto para qualitativas, é possível ultrapassar as incertezas, entretanto deve-se ter o cuidado de observar se ele está extremamente vinculado ao texto ou à técnica, num formalismo excessivo, que prejudique a criatividade e a capacidade intuitiva do pesquisador, levando-o a impor as suas próprias ideias ou valores, no qual o texto passe a funcionar meramente como confirmador dessas, uma vez que a análise de conteúdo como técnica metodológica também está sujeita aos problemas comuns da ciência.

Observando-se isso na fase da análise dos dados qualitativos com base na obtenção das motivações das sentenças, foi claramente possível encontrar inconscientes coletivos por trás de aparentes incoerências ou compreender estereótipos de papéis, como sugerido na hipótese principal da presente pesquisa.

Para o levantamento da coleta de dados foi elaborada a máscara de dados no Software SPSS (Statistical Package for Social Sciences), programa computacional de quantificação de dados, especialmente projetado para o processamento de dados e análise de estatística na área de Ciências Sociais (Bruni, 2009).

A metodologia foi definir 91 categorias de análise. Foram analisados 76 processos dos anos de 2011, em que foram encontrados 14 fundamentos de decisões. Para fins e amostragem foram intercruzados 10 processos com as 91 categorias mencionadas, totalizando 910 dados, que inicialmente confirmaram as hipóteses previamente estabelecidas da presença de códigos ideológicos (extralegais) nas decisões judiciais. 
Para que houvesse uma correta análise dos dados da pesquisa em estudo fez-se necessário uma orientação em três etapas: 1- pré-exploração do material ou de leituras flutuantes do corpus das sentenças; 2- a seleção das unidades de análise (ou unidades de significados); 3- o processo de categorização e subcategorização (Campos, 2004).

$\mathrm{Na}$ primeira fase, em que foram empreendidas várias leituras de todo o material coletado, houve uma interação significativa do pesquisador com o material de análise, o que lhe permitiu transcender a mensagem explícita e, de uma forma menos estruturada, conseguir visualizar pistas e indícios não óbvios.

No segundo momento, o investigador, que é orientado pelas questões de pesquisa que necessitam ser respondidas, selecionou unidades de análise (parágrafos). Essas unidades de análise foram categorizadas na terceira fase, ou seja, foi realizada uma operação de classificação de elementos constitutivos de um conjunto por diferenciação e, na sequência, por reagrupamento segundo o gênero.

Conjuntamente à formação das categorias, houve a codificação das unidades de análise para que essas não se perdessem na diversidade do material trabalhado. Isso posto, foram elaboradas três categorias: procedimentos e garantias, seletividade do sistema socioeducativo e metarregras do julgador, dentro das quais foram incluídos e intercruzados os dados anteriormente referidos, em termos de subcategorias.

Foram as categorias analisadas: a) Categoria: Fundamento das sentenças/metarregras do julgador; b) categoria: Seletividade do sistema socioeducativo

\section{ANÁLISE E DISCUSSÃO: DAS METARREGRAS (A PRODUÇÃO DE BODES EXPIATÓRIOS) ÀS VIOLAÇÕES DE DIREITOS E GARANTIAS FUNDAMENTAIS}

Ao serem analisados os dados, observa-se uma ratificação e solidez da ideia de existência da hipótese de que os julgamentos são baseados em estereótipos, reforçando-se a ideologia da defesa social. 


\subsection{Metaregras da proteção social e o escamoteamento da punição pela pedagogia da internação}

Em termos de análise da primeira categoria (Fundamento das sentenças/metarregras do julgador) verificou-se um perfil de quem é o adolescente definido como desviante: em $90 \%$ dos casos os adolescentes não estudam, $30 \%$ são analfabetos e $30 \%$ não completaram o $1 \square$ grau, mesmo com idades avançadas (60\% entre 14 e 15 anos e $40 \%$ entre 16 e 17 anos).

Devido a este quadro, em $60 \%$ das decisões há a fundamentação de que os adolescentes estão em risco pessoal e social, vulneráveis às influências negativas do meio. É o caso quando o julgador fundamenta a internação com a seguinte passagem: "O caso recomenda aplicação de MSE de internação em virtude do adolescente já encontrar-se inserido na criminalidade". ${ }^{4}$ Somado a este quadro, em seis das sentenças em que se valora a situação familiar, $66,7 \%$ entendem que os adolescentes não têm respaldo familiar para a ressocialização, por isso devem ser internados.

Por outro lado, $60 \%$ dos fundamentos das sentenças justificam a medida devido à dependência de drogas do adolescente, portanto incapaz de se ressocializar. Como se observa, levando em conta o marco teórico da criminologia crítica, a qual tem como fonte de origem a teoria da rotulação social e entende que o homem comum diferencia-se do delinquente tão somente devido ao processo de rotulação que sofre, tem-se que há um nítido processo de construção da criminalidade por parte do julgador.

A vertente teórica está sendo parcialmente demonstrada no sentido de que $\mathrm{o}$ ato infracional é uma realidade construída a partir da reação dos interesses prevalentes na sociedade, os quais estão fundados em estereótipos (pobreza, vulnerabilidade, influências negativas, dependência de drogas, falta de respaldo familiar). Estereótipos são preconceitos e subjetivismos, a representação ou ideia de um objeto, não necessariamente condizente com a sua realidade, que é compartilhada pelos membros da coletividade de forma consensual e estável (Goffman, 1988). 
O ato infracional não é uma realidade ontologicamente pré-constituída, mas realidade social construída por juízos atributivos do sistema de controle, determinados menos pelos tipos penais legais e mais pelas metarregras - o elemento decisivo do processo de criminalização -, aqueles mecanismos atuantes no psiquismo do operador jurídico, como estereótipos, preconceitos e outras idiossincrasias pessoais que decidem sobre a aplicação das regras jurídicas e, portanto, sobre o processo de filtragem da população criminosa (Santos, 2000, p. 173).

A grande prevalência de que existe um perfil de adolescente infrator - o marginalizado social - faz nascer um preconceito de que crime e pobreza são associados. Nesse contexto, o pobre basta surgir no cenário que se torna o suspeito número um, como se fosse o criminoso nato (Zaluar, 1994).

Diante disso, não se pode deixar de mencionar a hipótese de Zaffaroni, quando afirma que o poder punitivo sempre classificou e reconheceu um estranho, um indesejável, sobre o qual se aplicou um tratamento discriminatório, neutralizante e eliminatório, negando-lhe a sua condição de pessoa e considerando-o em função da sua condição de coisa ou ente perigoso. E mais, tanto as leis quanto a doutrina legitimam esse tratamento, baseadas em saberes pretensamente empíricos sobre a conduta humana. Tal doutrina-penal contradiz os princípios constitucionais do Estado de Direito e mais se aproxima do modelo de Estado absoluto. O Direito Penal sempre justificou e legitimou, com maior ou menor amplitude e prudência (ou imprudência), o tratamento de algumas pessoas como inimigas (Zaffaroni, 2007).

Associado a este quadro há ainda a latência da crença na defesa social, atuando como um significante nas decisões judiciais. A ideologia da defesa social é tida como o progresso das ciências penais, porque promoveu a racionalização, razão pela qual faz parte da Filosofia jurídica, bem como da opinião comum, constituindo-se numa espécie de every day theory. É um conceito construído por princípios, mas que assevera que há uma 
sociedade boa (não criminosa) que deve ser protegida por uma sociedade má, em que o Estado, por meio do Direito Penal, deve agir na proteção de todos para promover a prevenção a partir da punição (Baratta, 1999).

O maniqueísmo da divisão social funciona em termos de estereótipos (já discutidos) e a crença na possibilidade de o Direito Penal promover paz social é observada numa contradição: por um lado a atribuição de natureza penal às medidas socioeducativas, por outro a violação de direitos e garantias fundamentais dos adolescentes, pela crença de serem inimigos sociais, destituídos de cidadania do Estado Democrático de Direito, mas mascarado retoricamente pelo discurso pedagógico das medidas.

Isto se verifica quando os juízes entendem que a medida é necessária para o adolescente compreender o desvalor da ação. É o caso das fundamentações: "o crime causa comoção pública e deve ser punido com muito rigor".

Além disso, a característica maniqueísta está presente em oito sentenças que consideraram a periculosidade do adolescente como fundamento para a internação, seja mencionando isso explicitamente (75\%), seja referindo, mas não valorando como sendo suficiente para fundamento da internação (25\%).

Por fim, em 70\% das sentenças o julgador argumenta que a punição deve ser realizada para servir de exemplo para os demais adolescentes, intimidando-os. É o exemplo de quando textualmente assevera o julgador - "O ato infracional deve ser repreendido a fim de que a punição impere e a aplicação da justiça possa trazer mais tranquilidade à sociedade”. Apesar deste quadro de seletividade no momento do julgamento, porém, impera uma retórica pedagógica, quando o juiz revela que a medida tem natureza educativa, mas a usa para que se consolide um maior rigor na punição. Isto se deu em 100\% dos casos. Enfim, o que existe é a punição não por 
critérios objetivos, baseados na conduta violadora a bens jurídicos do adolescente, mas pela subjetividade do magistrado; tudo, porém, mascarado pelas ilusões de segurança (Andrade, 1997).

Toda esta estrutura é confirmada no processamento seletivo da responsabilização juvenil. O poder seletivo do sistema penal elege alguns candidatos à criminalização, cuja escolha, como visto, é feita em razão da pessoa (o bom candidato é escolhido a partir de um estereótipo), porém à agência judicial só é permitido intervir racionalmente para limitar essa violência seletiva e física, segundo certo critério objetivo próprio e diverso do que rege a ação seletiva do restante exercício de poder do sistema penal, pois, do contrário, não se justificaria a sua intervenção e sequer a sua existência (Zaffaroni, 2001).

Os códigos ideológicos encontrados nos fundamentos das sentenças influenciam todo o sistema de criminalização, desde o procedimento investigativo (inquérito policial) até a prolação da sentença, reproduzindo o alto grau de seletividade, como observado nos dados analisados. Foram observados como uma constância reveladora de perfis de seletividade: a escolaridade, a idade, o uso de drogas e a taxa de reincidência (60\% dos casos informados).

É importante atentar para o fato de que a maioria dos atos infracionais praticados são: $60 \%$ roubo, $20 \%$ tráfico e $20 \%$ homicídio, sendo um dos casos a tentativa. $\mathrm{O}$ que se quer destacar é que se somados os crimes contra o patrimônio e contra a saúde pública, tem-se que $80 \%$ dos casos guardam relação com o acesso à renda, ainda que de forma ilegal.

Uma realidade que se avulta quando os dados revelam que $90 \%$ dos adolescentes não têm ocupação produtiva, seja escolar seja laboral. Levando em conta uma sociedade globalizada e altamente capitalizada, cuja moeda de identidade e reconhecimento social é aptidão financeira, a criminalidade juvenil parece ser uma válvula de escape para a tentativa de pertencimento social (Bauman, 1999). 
Nesta lógica, quem é preso, processo e condenado desempenha o papel de criminoso, enquanto que os demais, não identificados como tal, permanecem desempenhando o papel de cidadão, respeitadores das leis (Becker, 2008).

Dessa forma, não significa que os membros das classes mais baixas têm maior motivação para o comportamento desviante, mas porque têm comportamentos mais visíveis e, consequentemente, maiores chances de serem etiquetados. A visibilidade é das condutas daqueles que não estão inseridos no mercado de consumo, de trabalho, etc., e o Estado, para escamotear sua ineficiência, transfere-os para o sistema penal, como uma “[...] continuada conversão de problemas sociais de complexa envergadura no código crime-pena, quando deveriam ser apreendidos e equacionados no espaço da cidadania” (Wacquant, 2003).

O processamento seletivo de responsabilização juvenil remete ao mecanismo do bode expiatório (Girard, 2008), no qual se produz uma vítima que é, por meio de um determinado escândalo, muitas vezes, hostilizada e culpada como única vítima (geralmente quem faz a denúncia), sem que se identifique uma regra geral para que norteie tal escolha.

Nesse mecanismo, acredita-se na existência de uma vítima escolhida de forma aleatória a partir de sinais indicativos, os quais são tomados como razões para vitimá-lo, e exatamente por isso é que estas razões são falsas, não podendo, portanto, serem consideradas aleatórias. Há ainda o fato de que tanto os situados no topo quanto os que estão no nível mais baixo da sociedade, ou seja, nos extremos, são mais escolhidos como bodes expiatórios do que as pessoas comuns das camadas intermediárias.

O mecanismo do bode expiatório é bastante frequente nas sociedades desde as civilizações antigas. O fator da escolha da vítima é recorrente nas sociedades, em que, ainda que inexistam sinais indicativos claros, qualquer coisa pode ser interpretada como sinal para a escolha do bode expiatório. Este mecanismo funciona, portanto, como uma falsa ciência, 
como algo que subitamente é relevado por meio da intuição. O que se infere, principalmente, desse famigerado mecanismo, é que quanto mais indiferenciadas forem as pessoas, mais fácil será decidir (por meio de estigmas, estereótipos, intuições e juízos de valor) que qualquer uma delas é culpada. Isso se dá em meio a momentos críticos na sociedade como forma de resolução de crises, pouco importando, no entanto, se a crise é real ou imaginária.

Válido se faz a transposição do trecho bíblico "Aquele que matar Caim será punido sete vezes”, pois corresponde à lei contra o assassinato na época, cujo fundamento é o assassinato ritual, no qual todos tomam parte, ao mesmo tempo em que ninguém é responsável. Confirma-se, portanto, a precedência do mecanismo do bode expiatório sobre qualquer forma de ordem cultural.

Na sociedade moderna, fragmentada com falhas de solidariedade na estrutura social, liderada pelo individualismo capitalista, na qual existem diferentes direitos de gozo à saúde, à educação, à profissão... o adolescente, perdido sem referenciais, quase não tem como suprir estas falhas na sua condição de sujeito desejante, terminando por figurar como candidato a bode expiatório.

Somado a isto, a ditadura da modernidade, travestida de igualdade (Calligaris, 1991), lança o sujeito na máquina do consumo e satisfação individual, reforçando o adolescente no estímulo e no ato de se eximir de responder por suas ações. E, considerando as formas de sociabilidade da modernidade, especialmente espetacular (Debord, 2003), em que os atores se inserem na vida social pela exibição e teatralidade, com exaltação do eu e estetização da existência, cujos gestos são de sedução do Outro e enaltecimento do eu, a definição dos “bodes” é emblemática.

Aliás, os jovens procuram uma obtenção de prestígio e saliência social indiscriminadamente, as quais passam a ser alcançadas por condutas de riscos, justificadas como a busca de novas experiências de prazer e 
emoção. Afirma-se que "sem rebeldia e sem contestações não há adolescência normal" (Osório, 1992). E ser selecionado é uma constante, sob o argumento de desvio, na verdade, tem-se um processo de inclusão e definição de identidades. $\mathrm{O}$ que existe, porém, é “um mecanismo invertido, em que a atenção é clamada de forma mórbida, os jovens encontram uma forma sucedânea e espúria de integração negativa que lhes permite ser identificados e reconhecidos como sujeitos únicos que carregam, outrossim, o estigma do rompimento" (Schecaira, 2008, p. 106).

No final das contas essa exacerbação (reconhecida por adjetivações - adolescentes em crises, vulnerabilizados, vitimados, em risco, em conflito com a lei, infratores...) produz discursos ideológicos para justificar práticas hegemônicas de controle de dominação - como o é para as mulheres, para os índios, para os negros, homossexuais, idosos... crianças, porém o controle é escamoteado pela "pedagogia".

\subsection{As Consequências do Julgamento para Educar: violações de direitos e a retomada de um modelo totalitário de tutela juvenil}

A hipótese que se levantou nesta pesquisa foi inicialmente verificada e a consequência prevista também se confirma. Ou seja, sendo os julgamentos baseados em códigos sociais extralegais, mas mascarados pela retórica socioeducativa, direitos e garantias fundamentais, constitutivos do Estado Democrático de Direito serão quase que necessariamente violados. É o que se apresenta a seguir.

1) O uso de interpretação extensiva utilizada em duas sentenças implica uma grave violação ao princípio da legalidade. $\mathrm{O}$ expediente é utilizado no caso de tráfico drogas, quando o artigo 122 do ECA só contempla como hipótese de internação violência ou grave ameaça à pessoa ou reiteração de atos, casos em que não se enquadram os casos apresen- 
tados. A impossibilidade de aplicar internação é reiterada na Súmula 492 do STJ: "O ato infracional análogo ao tráfico de drogas, por si só, não conduz obrigatoriamente à imposição de medida socioeducativa de internação do adolescente”.

2) O devido processo legal, garantia assegurada na legislação internacional - Regra 7.1 das Regras de Beijing, no artigo 5, LIV da CF e no artigo 110 do ECA - visa à proteção da pessoa contra a ação arbitrária do Estado, garantindo a paridade de armas em absoluta igualdade de condições com o Estado-persecutor e a plenitude de defesa e o contraditório. Ocorre que, nos delitos de tráfico de entorpecentes, em nenhum deles foi informada a quantidade de drogas e apenas em um deles foi realizada perícia.

Há uma nítida violação à materialidade do delito, implicando contraditório e defesa deficientes. Ainda em termos probatórios, em nenhum dos casos as provas são reproduzidas em juízo, prevalecendo a valoração da prova na fase policial, o que se deu em $100 \%$ dos casos. Ainda em termos probatórios, em $80 \%$ dos casos o adolescente confessou e, na maioria das vezes, esta foi a prova suficiente para a condenação, posto que não houve outros meios de prova, um paradoxo ante à súmula 342 do STJ que veda tal possibilidade. Testemunhas, quando presentes, em 37,5\% dos casos eram policiais que presenciaram o fato.

Paralelamente aos problemas de prova, tem-se muito claros problemas com a proporcionalidade, posto que se não se sabe a quantidade, não se pode assegurar que se tratava de tráfico ou de uso, cujas consequências deveriam ser necessariamente diversas. Em ambos os casos, porém, foi aplicada igualmente medida de internação, como se tudo fosse padronizadamente necessário. Nesses casos, a justificativa judicial era: "É necessária uma conduta mais enérgica, para que surta o efeito pedagógico esperado”. 
O âmago do devido processo legal é também violado quando se verificou uma debilitação da ampla defesa. Em todos os casos, a atuação foi de defensor público, cuja atuação foi tímida. Por exemplo, em 40\% não houve pedidos e em $30 \%$ dos pedidos que existiram não foram atendidos (30\% não foi informado). No dispositivo final da sentença em 60\% não há menção ao pedido do defensor, que variava entre absolvição e MSE diversa da internação. Inusitadamente, em um caso a própria defesa requereu MSE de internação.

Tais dados levam à constatação de uma desvalorização do pedido da defesa, que quando requerido, não é levado em conta pelo julgador (trecho extraído de sentença: "Não podemos pensar em pena mais branda, pois a justificativa da defesa de que o Estado é incapaz de proceder com ressocialização dos menores, não força aplicarmos pena mais branda”). Ocorre então que, no final das contas, a opinião da defesa não é valorada na decisão do juiz.

Outrossim, é de se ter em mente que em pelo menos dois dos casos analisados sobre tráfico de entorpecentes não caberia sequer internação (tráfico ilícito de entorpecentes) no final do procedimento, ainda que seguisse a "letra fria” da lei; quiçá internação provisória? Nos autos estudados, porém, entorpecentes surgem como uma grande mazela social (código ideológico) implicando uma tendência ao encarceramento, como se vê em trechos extraídos de sentenças: "O ato infracional praticado é infração de perigo à saúde pública, fazendo-se mister que o Estado-juiz adote a medida imperiosa da internação”; “Assim, entendo que a medida de internação, por ora, é a mais recomendável a ser aplicada ao representado, considerando a conduta do mesmo e, para que não volte a delinquir, tornando-se um profissional do tráfico, o que já é uma realidade”. 
Por fim, e não menos importante, percebeu-se que a exigência constitucional de fundamentação das decisões judiciais (artigo 93, IX) como consagração da legitimação racionalizada da justiça pública é constantemente desprezada e o fato a ser analisado é substituído por associação feita pelo juiz entre pobreza e criminalidade.

Há uma presunção de que os níveis sociais, bem como as influências do meio, estão completamente interligados, quase que como uma condição para a questão da criminalidade. São trechos de sentenças que exemplificam essa conclusão: “O caso recomenda aplicação de MSE de internação em virtude do adolescente já encontrar-se inserido na criminalidade"; "todos os representados têm histórico de vulnerabilidade social e familiar, com índices de vivência na rua, estando ainda mais latente a necessidade da MSE”; "Saliento que, ao mesmo tempo que a internação protege a sociedade, também resguarda a integridade física do adolescente infrator que, na grande maioria das vezes, encontra-se envolvido com quadrilhas de adultos já envolvidos na criminalidade há tempos”.

Como resultado obtido mediante cruzamento de dados no sistema Statistical Package for Social Sciences (SPSS), após análise de conteúdo realizada por categorização, observou-se uma confirmação da hipótese inicial de existência de uma criminalização secundária baseada em ideologias, pressão popular e estereótipos. Desse modo, a ação judicial é pautada por um alto grau de seletividade na criminalização secundária, na ausência de imparcialidade nos julgamentos e na violação de direitos fundamentais. De acordo com os dados, a existência latente de códigos ideológicos nos fundamentos das sentenças contamina e influencia todo o sistema de criminalização.

\section{PROVOCANDO REFLEXÕES}

Analisados os parágrafos anteriores, constatou-se uma postura ilegal e acrítica de juízes criminais que, ao condenarem réus acusados do ato infracional, fixaram regime prisional mais severo do que 
aquele permitido pela lei, além de se utilizarem de uma espécie de "fórmula retórica" para determinados tipos penais equiparados a ato infracional.

Em estudo dos diversos fundamentos das sentenças constatou-se que há um forte caráter ideológico presente na atuação dos juízes, que retratam sua filiação política e ideológica, sendo difícil sua dissociação, embora desejável em certa medida num regime democrático.

Em matéria penal, no entanto, esta filiação tem resultado em medidas extremamente repressivas, reveladoras de sua atuação à margem da lei. O resultado é a violação aos direitos humanos e a colocação em perigo das estruturas do Estado Democrático de Direito.

O resultado ilustra a necessidade do "pensar sociológico" diante da posição e interpretação dos sujeitos (juiz, Ministério Público, polícia judiciária/repressiva, bem como todos os sujeitos atuantes envolvidos no processo penal) da decisão de medida socioeducativa de internação, no momento em que fundamentam as sentenças, no caso do juiz, eivados de estigmas e preconceitos (os códigos ideológicos), que os instigam a decisões duras e positivadas sem levar em consideração o caráter social, econômico e familiar do jovem infrator.

A Sociologia Jurídica, ciência compreendida por muitos estudiosos como autônoma à Sociologia, cujo campo de estudo dedica-se à compreensão da organização e desenvolvimento de instituições, às formas de controle social empregadas, aos estudos de legislação, à interação entre culturas jurídicas diferentes, à construção social e ao debate de questões de cunho jurídico, às carreiras jurídicas e principalmente à relação entre direito e mudanças sociais, observando aplicabilidade, eficiência e obsolescência das leis, acredita que a perspectiva do fenômeno jurídico deve pautar-se na significação, na importância e na compreensão da atividade do 
profissional de Direito, no sentido de compreender que este é o guardião da Constituição e da defesa dos valores jurídicos sociais, afastando-se, ao máximo, do positivismo jurídico.

Diante dessa premissa, o marco teórico pelo qual se debruçou a presente pesquisa perpassou a proposta de Cláudio Souto (1987), segundo o qual o pensar sociologicamente não se contém na racionalidade lógica, mas crítica, condicionando a uma atividade judicante à busca da realidade social, a fim de haver uma interação do homem com seu meio social por meio de uma relação de alteridade. Desse modo, é justo e plausível que, por meio da Sociologia Jurídica, se busque a explicação e a compreensão da real eficácia jurídica na prática social, propondo novas reflexões hermenêuticas, de forma a proporcionar relações de alteridade e não de superioridade.

Para Souto, o "pensar sociologicamente" é ter uma compreensão científica - comprovável pela observação e controlada por intermédio de métodos e técnicas rigorosos de pesquisa - e crítica - a partir de variados pontos de vista e interpretações - da realidade social constituída e construída historicamente por todos e por cada um de nós.

Conhecer para compreender "realidades sociais" significa estarmos atentos para a forma como essas realidades se constituem, significa procurar leis e regras que organizam e orientam as sociedades, os grupos sociais, as culturas. Essas leis e regras não são fornecidas por si, são resultantes de procedimentos analíticos pensados profundamente a partir de observações rigorosas.

As leis e regras que ordenam a vida social - objeto de estudo da Sociologia - são proposições ou teses que tentam explicar (o que não significa emitir juízos de valor) a dinâmica social na qual cada um de nós está inserido. É reduzir estrategicamente a variação múltipla do real a poucas, mas abrangentes, categorias como interação, socialização, dominação, conflito. 
Essas categorias gerais explicam aquelas menos gerais, ou seja, os contextos, as particularidades, as singularidades. No campo das Ciência Humanas, contudo, são analisadas pessoas/sujeitos e não plantas ou rochas. Isto implica lidar com subjetividades, imprevisibilidades, significações, transformações.

Dessa forma, em que pese não prescindir de um método, o pensar sociologicamente é principalmente um exercício de imaginação criadora, propriamente humana. Desse modo não se deve condicionar a atividade judicante à busca da realidade social, a fim de haver uma interação do homem com seu meio social mediante uma relação de alteridade. Ao contrário, é justo e plausível que, por meio da Sociologia Jurídica, se busque a explicação e a compreensão da real eficácia jurídica na prática social, propondo novas reflexões hermenêuticas, de forma a proporcionar relações de alteridade e não de superioridade.

Deve-se, com o auxílio daquela, analisar-se a construção de decisões jurídicas, fazendo perceber a influência dos efeitos da política, das ideologias, dos preconceitos pessoais (juízos de valor dos sujeitos da decisão de medida socioeducativa de internação), ou seja, de como atuam os determinantes conotativos presentes no senso comum teórico e na singularidade do julgador, uma vez que, desse conjunto, surge a decisão.

Diante da orientação sociológica de Cláudio Souto (1987), mostra-se pertinente e necessária a proposta de Rosa (2004), técnica da bricolagem, cuja fundamentação se faz na análise dos significantes ao longo do processo e no momento da decisão judicial, valendo-se de profundas reflexões hermenêuticas na busca pela criticidade e desvinculação pessoal do juiz nas sentenças.

Com objetivo de amenizar os resultados de uma sentença eivada de ideologias e subjetivismos dos atores penais, Alexandre Morais da Rosa aposta em uma proposta alternativa para a construção das decisões penais: a bricolagem de significantes. Para que se compreenda o método 
da bricolagem, porém, bem como sua aplicação, é necessária uma sucinta discussão acerca da teoria garantista de Ferrajoli (modelo de compreensão da maneira pela qual se produz a decisão judicial). $O$ autor rejeita o modelo garantista, justificando que sua aplicação epistemológica não mais se aplica, uma vez que a decisão não está condicionada apenas à aplicação da lógica, mas também depende dos significantes, que seriam as concepções ideológicas, midiáticas, criminológicas e inconscientes.

Também critica a ideia do sujeito consciente da epistemologia garantista, pois, para ele, há ainda um sujeito inconsciente, sugerido pela Psicanálise, em que o sujeito consciente pensante pode atuar inconscientemente. Atrelada à insegurança da epistemologia garantista, é pertinente a discussão da (in)existência de um método universal.

Sabendo-se que a decisão judicial não traz as verdades anunciadas e que os métodos devem ser vistos como ferramentas, não devendo existir apenas um único método, Rosa afirma que a decisão deve ser fundamentada a partir da teoria de onde emanará o procedimento, não podendo ocorrer, como na realidade ocorre, a simples adequação dedutiva da conduta aos significantes probatórios entranhados aos autos. Caso contrário, poderá a decisão final resultar de um movimento tríplice (fixação da conduta típica - provas - retorno ao tipo penal) por parte do juiz, que geralmente recai na criminalização da pessoa pela lógica do "porque sim”, porque é a lei.

Consciente das deficiências do modelo garantista penal de Ferrajoli, é preciso que se compreenda o método da bricolagem, para que se faça a correta adaptação às peculiares decisões dos processos penais brasileiros. O bricoler (juiz) deve, ao longo do processo e no momento da decisão judicial, considerar todos os significantes produzidos na instrução processual. Dessa forma, o juiz não se vinculará à acusação, construindo sua decisão por fragmentos, de acordo com os significantes até chegar ao ato decisório. 
Nele, a partir das pretensões de validade enunciada pelas partes, o magistrado monta a verdade processual, utilizando-se para isso não só da lógica, mas do conjunto de significantes, constituindo, assim, a bricolagem, a qual é, portanto, um acerto de significantes que são influenciados por condicionantes inconscientes, materializados no ato decisório. Cabe ao jurista manejar os instrumentos dogmáticos de maneira crítica, trabalhando a linguagem jurídica e abdicando de argumentos retóricos e logicamente corretos.

Afinal, a total racionalização da pena na sentença pelos sujeitos do processo vai além do seu caráter discricionário, vai contra a função da atividade judicante, que é a busca pela realidade social/a verdade, transpondo uma relação de alteridade para uma de superioridade.

E se isto não for feito, tal como está, o que se tem é um retrocesso da Doutrina da Situação Irregular escamoteada pala Doutrina da Proteção Integral, a mesma tutela, mas nomeada de proteção.

\section{REFERÊNCIAS}

ANDRADE, Vera Regina Pereira de. A ilusão da segurança jurídica: do controle da violência à violência do controle penal. Porto Alegre: Livraria do Advogado, 1997.

BARATTA, Alessandro. Criminologia crítica e crítica penal: introdução à sociologia do direito penal. 2. ed. Rio de Janeiro: Freitas Bastos, 1999.

BARDIN, Laurence. Análise de conteúdo. Lisboa: Edições 70, 1977.

BAUMAN, Zygmunt. Globalização. As consequiências humanas. Rio de Janeiro: Jorge Zahar, 1999.

BECKER, Howard S. Outsiders. Rio de Janeiro: Zahar, 2008.

BRUNI, Adriano Leal. SPSS aplicado à pesquisa acadêmica. São Paulo: Atlas, 2009 . 
CALLIGARIS, Contardo. In: VVAA. Clínica do Social. Ensaios. São Paulo: Escuta, 1991.

CAMPOS, Claudinei José Gomes. Método de análise de conteúdo: ferramenta para a análise de dados qualitativos no campo da saúde. Revista Brasileira de Enfermagem. Brasília, vol. 57, n. 5, Set./Out. 2004.

DEBORD, Guy. A sociedade do espetáculo. São Paulo: Coletivo Periferia, 2003. FERRAJOLI, Luigi. Direito e razão - teoria do garantismo penal. 3. ed. São Paulo: Revista dos Tribunais, 2010.

GIRARD, René. O bode expiatório e Deus. Corvilhã: Universidade da Beira Interior, 2008.

GOFFMAN, Erving. Estigma - notas sobre a manipulação da identidade deteriorada. 4. ed. Rio de Janeiro: Guanabara, 1988.

MÉNDEZ, Emilio García. Infância e cidadania na América Latina. São Paulo: Hucitec; Instituto Ayrton Senna, 1998.

OSÓRIO, L. C. Adolescência hoje. Porto Alegre: Artes Médicas, 1992.

PRIORE, Mary Del. História das crianças no Brasil. São Paulo: Contexto, 1999. ROSA, Alexandre Morais da. Decisão no processo penal como Bricolage de significantes. 420 fls. Tese (Doutorado) - Setor de Ciências Jurídicas e Sociais, Universidade Federal do Paraná. Curitiba, 2004.

SCHECAIRA, Sérgio Salomão. Sistema de garantias e o direito penal juvenil. São Paulo: Revista dos Tribunais, 2008.

SANTOS, Juarez Cirino. O adolescente infrator e os direitos humanos. Discursos Sediciosos: crime, direito e sociedade, Rio de Janeiro, v. 9/10, p. 173, 2000. SARAIVA, João Batista Costa. Adolescente em conflito com a lei: da indiferença à proteção integral. 3. ed. rev. atual. Porto Alegre: Livraria do Advogado, 2009. SOUTO, Cláudio de Souza. O que é pensar sociologicamente. São Paulo: EPU,1987.

WACQUANT, Loic. Punir os pobres: a nova gestão da miséria nos Estados Unidos. Rio de Janeiro: Revan, 2003. 
ZAFFARONI, Eugenio Raul. O inimigo no direito penal. 2. ed. Trad. Sérgio Lamarão. Rio de Janeiro: Revan, 2007. Em busca das penas perdidas. 5. ed. Rio de Janeiro: Revan, 2001. ZALUAR, Alba. Condomínio do diabo. Rio de Janeiro: Revan, 1994.

Recebido em: 26/6/2015 Aceito em: 3/9/2015 